\title{
Article
}

\section{Inter-personal Violence and Abuse in Adolescent Intimate Relationships: Mental Health Impact and Implications for Practice}

Barter, Christine and Stanley, Nicky

Available at http://clok.uclan.ac.uk/15573/

Barter, Christine ORCID: 0000-0001-5682-5333 and Stanley, Nicky ORCID: 0000-0002-7644-1625 (2016) Inter-personal Violence and Abuse in Adolescent Intimate Relationships: Mental Health Impact and Implications for Practice. International Review of Psychiatry, 28 . pp. 485-503. ISSN 0954-0261

It is advisable to refer to the publisher's version if you intend to cite from the work. http://dx.doi.org/10.1080/09540261.2016.1215295

For more information about UCLan's research in this area go to http://www.uclan.ac.uk/researchgroups/ and search for <name of research Group>.

For information about Research generally at UCLan please go to http://www.uclan.ac.uk/research/

All outputs in CLoK are protected by Intellectual Property Rights law, including Copyright law. Copyright, IPR and Moral Rights for the works on this site are retained by the individual authors and/or other copyright owners. Terms and conditions for use of this material are defined in the policies page. 


\title{
Interpersonal Violence and Abuse in Adolescent Intimate Relationships: Mental health impact and implications for practice.
}

\begin{abstract}
This paper provides a narrative review of the knowledge on interpersonal violence and abuse (IPVA) in adolescents' intimate relationships. It draws on the authors' own research, published reviews and a rapid review on IPVA victimisation and mental health outcomes for adolescents. The research reviewed identified associations between adolescent IPVA and substance misuse, depressive symptoms and PTSD, eating disorders and suicidal thinking and behaviour in young people. Generally, girls appeared more likely to report severemental health outcomes than boys. Adolescents rarely disclose IPVA to adults and delivering preventative programmes that promote knowledge and help seeking may offer a means of building on young people's tendency to seek help from friends. These preventative interventions, usually delivered in schools, need to be closely linked to support services for adolescents who disclose abuse. While there are some practice examples of emerging interventions for both victims and perpetrators of adolescent IPVA, there is as yet little robust evidence regarding their effectiveness.
\end{abstract}

\section{Introduction}

There is increasing recognition in both policy and practice that interpersonal violence and abuse (IPVA) can be a feature of intimate relationships in adolescence. IPVA in young people's relationships differs from adult experiences of IPVA in some key respects. Most young people will not be sharing a household or co-parenting so economic dependence is not usually a factor. However, limited experience in intimate relationships means that young people often lack a sense of what constitutes 'normal' and acceptable behaviour in relationships and their repertoire of relationship skills and strategies may be limited (CutterWilson and Richmond 2011). Peer pressure and anxieties about social status loom large for adolescents and these may function to attract young people into and keep them in abusive relationships. Some groups of young people, such as adolescents in out-of-home care (Wood et al., 2011), appear particularly vulnerable to IPVA.

Although the term 'dating violence' is generally used in the US literature, this language does not necessarily transfer easily to other contexts (Barter 2009): in the UK, adolescents rarely describe themselves as 'dating'. In this review, the term 'adolescent interpersonal violence and abuse' (IPVA) will be used. There are few published definitions of IPVA that are specific to adolescent relationships and Cutter-Wilson and Richmond (2011) note a lack of consensus regarding definitions of teenage IPVA. For the purposes of this paper, we will adopt the definition developed by New Choices, a non-profit US agency working with victims of domestic violence and family abuse: 
' ....a pattern of actual or threatened acts of physical, sexual, and/or emotional abuse, perpetrated by an adolescent (between the ages of 13 and 18) against a current or former dating partner. Abuse may include insults, coercion, social sabotage, sexual harassment, threats and/or acts of physical or sexual abuse. The abusive teen uses this pattern of violent and coercive behavior, in a heterosexual or same gender dating relationship, in order to gain power and maintain control over the dating partner.' (http://www.newchoicesinc.org/educated/abuse/TDV/def (page 1)

This paper will not address the sexual exploitation of young people as there is a separate and distinct body of evidence on child sexual exploitation which is distinguished from IPVA by the fact that the sexually exploited child or young person receives something for sexual activities (Department for Education, 2012). Official recognition of adolescent IPVA differs internationally. The UK government definition of domestic violence and abuse was broadened in 2013 to include young people aged 16 and 17 and current debates suggest that the age range may be lowered still further in recognition that adolescent IPVA can occur at an even younger age (Fox et al., 2013, Barter et al , 2009a, Barter et al 2015 ). This widening definition of domestic violence makes IPVA in young people's relationships an issue for all services responding to domestic violence and abuse and for all those practitioners and clinicians working with adolescents.

However, while this increased recognition and policy attention is welcome, it has not necessarily been accompanied by improved service provision for adolescent victims/survivors or by interventions for young people who use violence against their intimate partners (Fox et al., 2013). As will be shown, the majority of research evidence, including robust evaluations of IPVA prevention programmes, originates from North America, making wider country comparisons difficult. Nonetheless, what seems to be common across the US and Europe is the lack of service provision for both adolescent victims and instigators. This service shortfall may contribute to a higher demand on services in the future as adolescent IPVA victimisation is one of the main predictors of victimisation in adult life for women (Whitfield, 2003; Murrell et al., 2007). Below, we discuss the prevalence of IPVA in adolescent relationships and we then report the evidence from a rapid review examining the relationship between IPVA in adolescent relationships and mental health outcomes. We address the service response by examining identification and disclosure which represent a major challenge in adolescent IPVA and then move to explore whole population approaches to prevention, a field where practice and research are more developed, especially in North America. Finally, we consider what evidence there is of services for adolescent victims and perpetrators, noting the role that schools and mentors can play in providing a sensitive response.

\section{The Extent of Adolescent IPVA}

Research has generally focused on three forms of adolescent IPVA: physical; sexual and emotional/psychological; although more recent studies have included an additional category of IPVA through new technologies. IPVA through new technologies typically consists of five main elements: emotional online abuse (e.g. posting nasty/derogatory online messages); 
controlling behaviour (e.g. using mobile phones or social networking sites to try and control who someone can friends with/where they go/or how to dress); surveillance (e.g. constantly checking on what partners have been doing /who they you have been seeing), social isolation (e.g. attempting to isolate partners from friends by posting untrue/derogatory messages from their phones etc.) and coerced sexting (Wood et al., 2015). However, in practice, different forms of IPVA often co-exist.

How common is IPVA in adolescent relationships? Two recent evidence syntheses (Stonard et al 2014, Wincentak et al 2016) concluded that prevalence rates for IPVA in young people's relationships vary considerably depending on the populations sampled, definitions used, forms of IPVA included and the acts incorporated, although the latter only addressed sexual and physical IPVA. Stonard et al (2014) found that around half of all young people reported some form of emotional victimisation and between 50 and $70 \%$ of IPVA through technologies depending on the acts included. Although pressured sexting and unwanted sharing of sexual images appears to be primarily experienced by girls (see also Wood et al., 2015, Drawker and Martsold, 2010, Zweig et al., 2013).

Both reviews identified that approximately $20 \%$ of young people experience physical victimisation from a partner. Establishing prevalence for sexual victimisation was more challenging, although both reviews conclude rates were higher for girls than boys. Stonard and colleagues used a wide definition of any unwanted sexual contact report rates of between $26-33 \%$ for adolescent females and $23 \%$ for males. A more restricted definition of unwanted sexual intercourse yielded rates of 2-19\% for females and $6 \%$ for males. The latter are roughly comparable to Wincentak et al's (2016) findings of $14 \%$ and $8 \%$ respectively. Although both showed significant variations in rates across studies: from $1 \%$ to $61 \%$ in Wincentak et al's review. Studies which include same-sex adolescent relationships indicate that rates are similar, although some forms of abuse such as forced 'outing' are specific to this group (Martin-Storey, 2015, Goodenow and Meer, 2013, Barter et al., 2009a, Halpern et al., 2004).

Stonard et al (2015) conclude that IPVA represents a significant problem and that gender is only a factor for sexual violence victimisation. This contrasts with adult domestic violence where, although males can be victims, predominantly women face the burden of IPVA: women's experience of domestic violence is more severe and prolonged than that of men and has greater impact (Walby and Allen, 2004, Ansara and Hindin, 2009).

However, a number of studies show that greater proportions of adolescent females report more severe forms of IPVA (Barter et al., , 2009a, Foshee, 1996, Wolitzky-Taylor et al., 2008). Hamby et al (2012) established that more girls than boys reported fear and injury. Jackson et al (2000) in their New Zealand study also reported that girls experienced more negative emotional responses to IPVA victimisation than did boys. Other studies show that girls are more likely to be hurt or require medical attention than boys, whilst boys report laughing about the violence perpetrated against them (Foshee, 1996; Molidor et al., 2000, Barter et al , 2009a, Wood et al., 2011, Barter et al., 2015). Barter et al's UK (2009a) and Barter et al's European (2015) cross-sectional studies show that girls report a significantly greater negative impact from physical and sexual IPVA, most often feeling scared, upset and 
humiliated, compared to boys who most often reported that they found it funny. Online abuse and face-to-face emotional abuse were more likely to evoke a negative response from males (most often feeling annoyed and angry) and females. This may indicate that emotional and online forms of abuse and control cannot be so easily laughed off by male recipients. Another possible explanation is that adolescent boys may be reluctant to report feelings associated with vulnerability, such as being scared of violence, due to stereotypical concepts of masculinity (Connell, 1987) which may apply more readily to physical violence. This gendered disparity in impact may be elucidated further through consideration of the mental health impact of adolescent IPVA victimisation, to which we now turn.

\section{Methodology}

A rapid review was undertaken to examine the available research evidence on mental health outcomes of IPVA victimisation in adolescence within a shorter timescale than a more traditional 'systematic review' (Ganann et al. 2010). A rapid review uses systematic review methods to search and critically appraise existing research but makes concessions regarding the breadth or depth of the review process. The PubMed bibliographic database was determined to be the most relevant. No time constraints were placed on the review as this literature is relatively recent with no publications pre-dating 1990 . The search was undertaken in December 2015 and updated in June 2016. In addition, the references of included studies were also screened for additional papers.

The terms used for PubMed advanced search (title and keywords only) were: adolescen*; young people; youth*; dating violence; intimate violence; mental health. The criteria for inclusion in the rapid review were:

1) included physical, sexual, emotional/psychological and/or online forms of IPVA;

2) baseline sample was under the age of 18 (or18 year-olds constituted only a minority of the sample $<20 \%{ }^{1}$ );

3) retrospective accounts of IPVA before the age of 18 years old;

4) measured some aspect of mental health or psychological functioning which was broadly defined as including substance misuse and unhealthy weight control as well as depressive symptoms, diagnosed disorders and suicidality;

5) longitudinal or cross-sectional design.

The above search yielded 179 abstracts which were screened against the inclusion criteria and a large number were excluded at this stage $(n=139)$. The resulting 40 publications were assessed according to the adequacy of the methodological information and detail, and the suitability of the methodological framework in order to present only findings from reliable and rigorous studies. Specifically, studies were appraised on the clarity of their research question(s) and the appropriateness of the research design, whether the sample size was drawn from an appropriate population and was adequate to support the quantitative analysis

\footnotetext{
${ }^{1}$ due to a number of US high school studies which included a small proportion of year 12 pupils aged 18.
} 
undertaken, whether the data collection and analysis was described in sufficient detail to ensure confidence in the findings and whether the conclusions were substantiated by the data.

This resulted in 33 publications (see Table One) being included in the review. Of these only six used a longitudinal design (Borowsky et al 2001, Ackard et al., 2007, Jouriles et al 2008, Schad et al 2008, Exner-Cortens et al., 2012; Van Dulmen et al 2012). The remainder used a cross-sectional design and all authors acknowledged the limitation of this methodology for determining causation: whether the mental health indictor was a precursor to IPVA, a consequence or both. All of the studies are based on North American samples and we need to be cautious in applying these findings directly to other contexts and cultures (Barter , 2009, Barter et al., 2015). However, they do provide important messages in relation to the association between intimate violence and young people's mental health. Statistical results are presented for some studies to aid clarification.

In respect of interventions for IPVA in adolescence, the authors were able to utilise their recently published systematic review of preventative interventions (Stanley et al 2015a) to provide an up-to-date picture of the evidence. There is however, very little published evidence available in relation to secondary interventions for young people who experience or perpetrate IPVA and the final sections of this paper therefore rely on the authors' own expertise and knowledge networks.

\section{Results}

The 33 papers covered four aspects of adolescent mental health: substance use; depressive symptoms/diagnosed mental health disorder; suicidality; and eating disorders. These are discussed in turn below.

\section{Substance use/misuse (alcohol; illicit drugs)}

The largest range of studies addressed associations between IPVA and substance use. The most commonly used measures were; alcohol use; and /or illicit drug use, most generally marijuana. Overall, the research findings demonstrate that IPVA victimisation is significantly associated with substance use, although findings vary by type of abuse, substance and gender.

Silverman et al's (2001) early cross-sectional study based on female participants $(1997 ; 1999$ Massachusetts Risk Behaviour Survey cohorts) identified that approximately $20 \%$ reported being physically and/or sexually abused by a 'dating' partner. Amongst wider health risks they found that IPVA victimisation was independently associated with an increased risk of all forms of substance use including binge drinking and cocaine use (e.g. cocaine use for 1997, OR, 4.7; 95\% CI, 2.3-9.6; for 1999, OR, 3.4, 95\% CI, 1.7-6.7). Addressing boys' experiences Howard et al (2008) analysed male adolescent experiences of physical dating violence victimisation and found an association with substance abuse. Eaton et al's (2007) cross-sectional study and Ackard et al's (2007) two-wave longitudinal study both found an association between IPVA victimisation and substance use for female participants but not males. A large representative study $(n=27,758)$ also established that frequent or recent alcohol and marijuana use was associated with IPVA victimisation, although no gender 
breakdown was provided (Parker et al., 2015). Temple et al (2011) examined the association between IPVA victimisation in an economically disadvantaged sample of US high school students and a range of licit and illicit substances, including the use of glue, ecstasy, vicodin and Xanax. Overall, their findings show that adolescents who used alcohol and controlled substances, irrespective of gender, were over three times more likely to report IPVA, a finding reflected by Zaha et al (2013). Small longitudinal studies by Schad et al (2008) and Raiford et al (2007), with African American adolescent females, also found an association between IPVA victimisation and later increased alcohol and/or substance use.

Others have used a wider definition of IPVA to include verbal and online forms of abuse. Using a nationally representative sample of US adolescents, Haynie et al (2013) measured victimisation and perpetration of verbal and physical IPVA. They found that, compared to non-abused youth, respondents who reported verbal only or verbal and physical IPVA were more likely to report alcohol use. Female victims were also more likely to report marijuana use. This gender divide was confirmed by a subsequent study using the same data with a five year follow-up by Exner-Cortens et al (2012). For females, psychological victimisation was predictive of heavy episodic drinking ( $\mathrm{aOR}=1.44$; 95\% CI 1.03-2.01) whereas for males psychological victimisation was predictive of marijuana use (aOR=1.34; 95\% CI 1.03-1.74). In contrast, Bonomi et al's (2013) research based on retrospective accounts of university students' experiences of adolescent physical, sexual and online IPVA found no association with alcohol or illegal substances, although wider mental health outcomes were reported.

A minority of studies report on younger children's experiences. Swann et al (2008) found that pre-teen alcohol use was associated with later IPVA victimisation and perpetration irrespective of gender. Others have identified that substance can be both a precursor and consequence of IPVA (Olsen et al., 2010). Lormand et al's (2013) research addressed the IPVA experiences of younger adolescents (mean age 13 years) and substance use. They found that physical, non-physical and any form of IPVA victimisation was associated with an increased risk of ever using drugs and ever using alcohol.

Only one study included a population-based sample of adolescents with disabilities (Mitra et al., 2013). Using data from the Massachusetts Youth Heath Survey, they found that disabled girls and boys who reported ever being on a date were more likely to report IPVA than their non-disabled counterparts. Only health outcomes for female participants were reported due to low counts for boys. Disabled girls who reported IPVA victimisation were more likely to say they had used both alcohol and drugs in the previous month compared to non-abused disabled girls ( $\mathrm{aOR}=4.3,95 \% \mathrm{CI} 1.6-6.3$ ) and victimised girls without a disability (aOR $=4.7,95 \% \mathrm{CI}$ 1.6-6.0). We located a single study which addressed adolescent same-sex IPVA experiences and substance use. Martin-Storey (2015) found that binge drinking was associated with IPVA in female same-sex relationships, whereas for boys this was only significant for those who reported an uncertain sexuality status.

Overall, it may be that IPVA is associated with greater risk taking generally, including substance use (Rothman et al., 2012, Eaton et al., 2007). Conversely, substance use may create contextual vulnerability (Vezina and Hebert, 2007) where adolescents have less selfcontrol, fewer inhibitions and reduced communication skills (Haynie et al., 2013). Lastly, 
adolescents may use substances to cope with the emotional impact of IPVA and this may be gendered (Haynie et al., 2013). Generally, the findings strongly suggest that substance use is both a risk factor and an effect of IPVA victimisation, in both adolescence and young adulthood.

\section{Depressive symptoms/diagnosed mental health disorder}

A variety of measures have been applied in the research to determine the association between adolescent IPVA and mental health disorders, with depressive symptoms being most regularly identified (for example Holt and Espelage, 2005, Banyard and Cross, 2008, Shad et al., 2008).

Longitudinal research has shown IPVA victimisation to be predictive of later depressive symptoms, typically: dysthymatic mood; hopelessness; sleep disturbance and anxiety (Ackard et al., 2007, Schad et al., 2008, Exner-Cortens et al., 2012, Haynie et al., 2013).

In an early longitudinal study, Ackard et al., (2007) used a composite measure of depressive symptoms based on: fatigue; sleep disturbance; dysthymic mood; hopelessness; feeling tense /nervous; and worry. Respondents placed in the highest quartile were defined as exhibiting high depressive symptoms. They found a significant association between depression and female IPVA victimisation $(\mathrm{OR}=1.92 ; 95 / 5$ ci $1.22-3.00<.005)$. No association was found for adolescent males. This association has also been identified with disabled female adolescents (Mitra et al., 2013), who reported greater levels of depression than their nondisabled counterparts (aOR=3.1, 95\% CI 1.6-6.0). Similarly, Bonomi et al's (2013) study using retrospective accounts of adolescent IPVA found an association between all types of IPVA measured (physical, sexual and online) and depressive symptoms (feeling down/hopeless; lost interest) for female adolescents. For males, no differences were found in relation to depressive symptoms between abused and non-abused groups. Haynie et al's (2013) representative study addressed depressive symptoms and wider psychological complaints (feeling low, bad temper, nervousness and difficulty sleeping). In contrast to the previous findings, IPVA victimisation was associated with greater depressive symptoms for both girls and boys, reflecting other studies (see Banyard and Cross, 2008). This was found to be consistent across different elements of depressive symptoms (sadness, irritability and hopelessness, ability to pay attention at school, changes in sleep and eating) over a 30 day time frame and reports of psychological complaints over a six month period. Females who reported both verbal and physical IPVA exhibited severer depressive symptoms than those who reported verbal victimisation alone; no difference was found by type of IPVA for males. In contrast Jouriles et al's (2008) small cross-sectional study found an association between psychological IPVA and psychological distress, after controlling for physical IPV and age $\left(\right.$ Wilks' $\left.^{\prime}=.84, \mathrm{~F}(3,113)=7.27, \mathrm{p} \leq .001,2=.16\right)$, However , physical IPVA was not associated with psychological distress. The he authors conclude that non-physical forms of IPVA require careful consideration.

Others have also identified post-traumatic stress in IPVA adolescent victims (Singer et al., 1995). In a small study of US high school students ( $n=190)$ Callahan et al., (2003) found that for girls, increasing levels of IPVA (severity, frequency, injury) were related to higher levels 
of post-traumatic stress and dissociation (trauma symptom checklist for children (TSCC) using the posttraumatic stress and dissociation subscale); whilst for boys, the levels of victimization were related to higher levels of anxiety, depression, and posttraumatic stress.

Wolitzky et al (2008) used a restricted definition of severe physical and sexual IPVA (badly beaten up; injury; threat of a weapon/forced sex), which resulted in prevalence rates of $2.7 \%$ of girls and $0.6 \%$ of boys. Post-traumatic stress disorder was measured by a structural diagnostic interview assessed each DSM-IV symptom; validated against the PTSD module of the Structural Clinical Interview. A significant association was found between IPVA victimisation and PTSD (OR 3.58; 95\% CI, .92-6.71).

One study (Volpe et al 2012) sought to examine the relationship between physical IPVA victimisation, depression and relationship power (ability to act independently despite a partner's wishes; to control a partner's actions; and have decision making powers) amongst a small sample of low-income disadvantaged urban adolescent girls (n-155). They found that girls reporting relationships characterised by IPVA accompanied by low relationship power (little control and power) showed greater depressive symptoms than those reporting IPVA in isolation. This reflects the findings of research by Decker et al (2014) whose research sits outside our sample criteria (includes 15-19 year olds) but warrants acknowledgment. They examined the health outcomes of disadvantaged female adolescents across vulnerable urban environments globally $(\mathrm{n}=1,112)$ and found an association between IPVA and mental health in countries where numbers allowed analysis.

A smaller number of studies conclude that early onset psychiatric disorders represent a risk factors for later IPVA victimisation and instigation (Mass et al., 2010, Lehrer et al., 2006, McCauley et al., 2015), although these studies generally use a wider-age range (up to 21 years) than specified within this review. One of the only studies utilising a clinical youth sample which although again sits outside our age criteria is also worth acknowledgment. Brown et al (2009) found adolescents seeking help for a mental health issues with a reported history of IPVA had increased rates of psychiatric disorders (comorbid Axis 1 disorders) and lower psychosocial function compared to non-victims at both base-line and six month followup. Additionally, respondents with IPVA experiences did not make the same level of improvement in their mental health status as non-victims.

\section{Suicidality}

A number of studies have identified an association between IPVA and suicide ideation or actual suicide attempts for both female (Ackard et al., 2007, Coker et al., 2000, Silverman et al., 2001, Olshen et al., 2007, Ackard and Neumark-Sztainer, 2002, Howard and Wang, 2003) and male adolescents (Ackard et al., 2003, Ackard et al., 2007, Howard et al., 2008). Similarly, studies addressing youth suicide have identified wider aspects of peer violence as a major risk factor (Borowsky et al., 2001., Garrison et al., 1993, Resnick et al., 1997, Woods et al., 1997, McKeown et al., 1998), although only Borowsky et al (2001) included IPVA. Swahn et al's (2008) cross-sectional data on youth peer violence and relationship violence found a correlation with suicide behaviour. Kreiter et al (1999) identified a similar association for girls but not boys (aOR, 1.55; 95\% CI 1.30 -1.85). 
Sexual IPVA has also been associated, in cross-section studies, with adolescent suicidal thinking and behaviour. Ackard and Nuumark-Sztainer (2002) found that suicide ideation was greater for female victims of IPVA, with $50 \%$ of those reporting physical and sexual IPVA also reporting attempted suicide (OR: girls $=5.78$; boys $=6.66)$. Correspondingly, Silverman et al., (2001) found that physical and sexual IPVA was significantly associated with suicide ideation in both female cohorts (for 1997, OR, 7.6; 95\% CI, 4.7-12.3; for 1999, OR, 8.6, 95\% CI, 5.2-14.4). A more recent cross-sectional study based on a representative US sample by Belshaw et al., (2012) analysed relationship violence and suicide controlling for wider sexual assault and drug use. They incorporated four suicide measures: suicide attempts; injured from suicide attempt; considered suicide, made a suicide plan. Overall, female respondents were more likely to report suicide ideation or taking suicide action than males. Their findings on IPVA showed that physical IPVA victims were twice as likely to consider or attempt suicide, after controlling for drug use and non-date sexual assault, than non-victims (Exp (b)'s $=1.85$ and 1.86, $\mathrm{p}<.001$ respectively). Adolescents reporting physical IPVA were $62 \%$ more likely to attempt suicide than non-physical victims (Exp (b)'s $=.619$ $\mathrm{p}<.001$. No significant gender differences were reported (Belshaw et al., 2012). However, Van Dulmen et al's (2012) longitudinal study found that although suicidality did increase the risk for IPV victimization, IPV victimization did not increase risk for suicidality irrespective of gender.

The accumulative evidence indicates that many young people experiencing IPVA victimisation lack adequate or positive coping strategies (Belshaw et al., 2012) and resort to destructive patterns to cope with the psychological effects of violence and abuse, although as we have seen some evidence disputes this association and instead suggests that suicidality should be viewed as a risk factor for later IPVA victimisation (Van Dulmen et al., 2012).

\section{Unhealthy weight control}

Fewer studies have addressed the association between unhealthy weight control and IPVA. Both Silverman et al., (2001) and Thompson et al., (2001) identified an association between physical and sexual IPVA and unhealthy weight control for female adolescents (eg use of laxatives and or vomiting: Silverman for 1997, OR, 3.2; 95\% CI 1.8-5.5; for 1999, OR, 3.7; 95\% CI, 2.2-6.5). A similar link has been found for both females and males in crosssectional research (Ackard and Neumark-Sztainer, 2002, Ackard et al., 2003, Cha et al., 2016), although results varied by race and ethnicity (Cha et al., 2016). However, a longitudinal study (Ackard et al., 2007) only found an association between IPVA and binge eating for males, with no associations with more extreme weight control methods. Bonomi et al's (2013) study, which included a wider range of IPVA victimisation types, found that, for girls, all forms of IPVA victimisation (physical, sexual, non-physical) were significantly associated with eating disorders (sexual/physical victimisation at increased odds of using diet aids, $P R=1.98$; fasting $P R=4.71$; vomiting $P R=4.33$; non-physical victimisation fasting PR3.37; vomiting $P R=2.66$ ) whilst, for boys, only non-physical IPVA was associated with disordered eating (using diet aids; fasting; vomiting PR=2.93). This mirrors Exner-Corten et al's (2012) longitudinal work which also found that, five years after physical and/or sexual 
IPVA victimisation, female adolescents showed an increase in depressive symptoms compared to the non-abused group ( $b=0.09 ; 95 \%$ CI 0.12$)$; in contrast, no association was found for males.

\section{Combined mental health problems}

The rapid review identified a single study (Ackard et al., 2007) which utilised a combined mental health impact measure. A composite risk index factor was created - if an individual reported three or more of the following behaviours/conditions they were judged to be high risk: extreme weight control; binge eating; suicide ideation; suicide attempt; smoking cigarettes at least monthly; drinking alcohol at least weekly; smoking marijuana at least monthly; high body dissatisfaction; high depressive symptoms; or low self-esteem. In the overall sample, $31.6 \%$ of females and $14.7 \%$ of males were categorised as high risk. For those reporting IPVA victimisation, this increased to $50 \%$ for females and $30.4 \%$ for males compared to $27.4 \%$ and $13.1 \%$ respectively of non-victims. The authors state that IPVA is a significant but non-specific risk factor for the behavioural and psychological health of youth, particularly female adolescents.

In summary, it seems clear that adolescent IPVA is associated with a range of psychological symptoms and risk behaviours. As Haynie et al., (2013) conclude, 'limitations notwithstanding, our findings showed adverse health in adolescents exposed to physical/sexual and non-physical types of dating violence, particular victimized females' ( $p$ 9). However, our rapid review indicates that the evidence is far from conclusive in respect to the gendered mental health impacts of adolescent IPVA. Nevertheless, on balance, there does seem to be sufficient weight to support the argument that, as with adult IPVA, adolescent girls and boys experience differential IPVA outcomes, with girls reporting greater negative impact on mental health.. We now turn to consider identification and intervention in adolescent IPVA.

\section{Identification and Disclosure}

Research has consistently shown that young people rarely seek help or spontaneously divulge their experiences of relationship violence and abuse to adults, including professionals (Barter et al., , 2009a, Barter et al., 2015). Rickert et al (2009) reviewing the US data state that evidence on help-seeking and disclosure strongly underscores the importance of systematic screening for violence in young relationships. Brown et al (2009) conclude from their small $(n=98)$ clinical study ' $[\mathrm{t}]$ he results indicate that young people who present to mental health services often encounter a number of adversities, interpersonal violence among them', continuing that ' $[\mathrm{m}]$ ental health services could be an important avenue through which to screen for and identify (interpersonal) violence in those attending for other reasons' (pg 1976). How, best to undertake these procedures and what measures are most appropriate remains under-examined (Olson et al., 2004). A randomised-control trial of an audio-assisted computer interview screening procedure for violence in young relationships involving 699 
young people aged 15-24 in a US sexual health setting found enhanced detection of recent victimisation compared to the control groups (who were asked to provide a basic health history) (Rickert et al., 2009). The screening procedures were viewed positively by participants but the extent to which this approach is applicable to adolescent mental health settings remains unclear. However, screening is only one approach to identifying IPVA among young people and a systematic review of the evidence for screening women in health settings for domestic abuse found a lack of evidence for its effectiveness and acceptability (Feder et al., 2009). Targeted enquiry may be a more appropriate and sensitive strategy for health care professionals in mental health, sexual health and primary care services. It may also be productive to build on young people's own patterns of help seeking. Barter et al's (2015) survey of teenagers in five European countries found that young people were most likely to disclose experiences of IPVA to their friends. Seventy-four percent of those who had experienced IPVA had told someone about it and 64 percent of those who did so confided in a friend whilst only 17 percent spoke to an adult (Hellevik et al., 2015). In line with previous research (Jackson et al., 2000, Barter et al., 2009a), more girls than boys, regardless of the type of abuse experienced, had sought support about the abuse they had experienced. The likelihood of young people confiding in friends in the first instance and their preference for informal and confidential sources of help is well documented across a number of areas of need (Featherstone and Evans, 2004; Gorin, 2004).

\section{Whole Population Approaches to Prevention}

Prevention programmes delivered in schools offer another approach to early identification of IPVA in young people and a UK mapping study (Stanley et al., 2015a) found that, although provision was patchy and often unsustained, a range of domestic abuse prevention programmes were being delivered in secondary schools. Increasing knowledge, awareness and help seeking in relation to IPVA across whole populations of young people constitutes a means of maximising the support that young people can offer one another: adolescents who have learnt to recognise abusive and controlling behaviour as such and who are familiar with relevant sources of support can direct their friends to use them. A range of 'dating violence' prevention programmes have been developed and tested in North America and systematic reviews of the evidence for their effectiveness have found that they have impacted on knowledge and help seeking in relation to interpersonal violence although effect sizes are generally low to moderate (Whitaker et al., 2006; Fellmeth et al., 2013;Stanley et al., 2015a). In addition, some programmes have achieved behavioural change in terms of boys' use of violence (Wolfe et al., 2009). Stanley et al (2015b) highlight the importance of a school's readiness to deliver these interventions and the value attached to authenticity in programme content and delivery by young people.

A group of these programmes described as bystander interventions have emerged more recently and such interventions define interpersonal violence as a community problem and aim to empower young people of both genders to recognise and challenge IPVA amongst their peers when they encounter it (Katz et al., 2011; Miller et al., 2012). These programmes harness social norms theories and capitalise on young people's inclinations to look to their 
peers for support (World Health Organisation (WHO), 2009). Both Katz et al., (2011) and Miller et al., (2012) report a positive impact on attitudes, knowledge and behaviour but the Coaching Boys into Men programme encountered difficulties when the programme designers attempted to translate it to Mumbai, India (Miller et al., 2014). At present, most of the evidence on preventative programmes for adolescents derives from high income countries (WHO, 2015).

Whole population approaches to the prevention of IPVA in young people's relationships also include the use of media campaigns. Young people's high levels of use of a wide range of media make this approach particularly congruent. Their media literacy offers opportunities for young people themselves to participate in the creation and delivery of such campaigns so increasing their authenticity and relevance for adolescent audiences (Stanley et al.under review). Although there is little peer reviewed literature addressing media campaigns for this audience, there are practice examples available of IPVA prevention campaigns for young people and some of these are reported via 'grey' literature (see Hester and Westmarland, 2005; Reid Howie Associates, 2002). The most notable of recent UK campaigns is the Home Office's This is Abuse campaign which addressed coercion and sexual abuse in teenage relationships using young characters from a popular television soap series. This achieved a high profile through the use of television and was delivered in several waves from 2010 onwards. While some evidence of impact is available from the evaluations conducted by the Home Office, no large-scale robust evaluation of the campaign's impact has been undertaken (Stanley et al.,2015a).

The consultations undertaken with young people and experts for Stanley et al 's (2015a) review emphasised the importance of schools that deliver preventative work forging strong links with supportive services for young people who disclosed experience of IPVA consequent to participating in such a programme. Indeed, education experts contributing to the consultations argued that a lack of such services acted as a deterrent to engaging with IPVA prevention work since schools were anxious that delivering preventative programmes might elicit disclosures that they lacked the skills or resources to handle (Ellis et al., 2015). Young people contributing to the consultations argued that: 'It makes people aware but then they need the help afterwards' (Young People's Consultation Group 1, Stanley et al., 2015a, p.102). Linking prevention work to relevant support services for young people offers a means of connecting prevention with early intervention in this field but, as the next section will demonstrate, relevant support services have been slow to develop.

\section{Interventions for Young People Experiencing IPVA}

In England and Wales, National Institute of Clinical Excellence (NICE) guidance (2014) on the health and social care service response to domestic violence and abuse states that those responsible for safeguarding children, commissioners and service providers should 'provide support and services for children and young people experiencing domestic violence and abuse in their own intimate relationships' (Recommendation 11). However, services that are 
specific to adolescents experiencing IPVA in their own relationships are rare and most of the interventions that have been robustly evaluated are those that aim to assist the recovery of young people who have been exposed to IPVA in their parents' relationships (see Howarth et al., forthcoming). While interventions designed for those experiencing IPVA in their parents' relationships often take the form of group programmes, some interventions targeted on the individual young person are sufficiently flexible to address both experience of domestic abuse at home and experience of IPVA in adolescents' own intimate relationships. For instance, the UK KIDVA service described by Westwood and Larkins (2015), which delivers both individual advocacy work and group work to young people, addresses both these experiences of abuse. Westwood and Larkins (2015) highlight the service's investment in using flexible forms of communication to develop and maintain trusting relationships with adolescents who had experienced IPVA victimisation and there is increasing interest in using new technology to raise awareness and to offer support to young people experiencing IPVA. Initiatives include a mobile phone advice service provided by Mobieg in South Africa (http://www.mobieg.co.za/home/what-is-mobieg-about) and an app available in five European languages (stiritup.eu/app-and-resources) designed to assist young people recognise abuse in their intimate relationships.

Most of the work to date in the UK on developing interventions to support adolescents experiencing IPVA in their own relationships appears to be concentrated in the independent/non-profit domestic abuse sector. SafeLives, a UK charity working to combat domestic violence, has developed a range of practice messages for engaging with young people experiencing IPVA and these are available as briefing papers (SafeLives, 2013 and 2015). The briefing papers emphasise the need for practitioners to spend time exploring the nature of abuse since young people may not identify their own experiences as abusive. SafeLives (2015) also stresses the importance of validating the serious nature of young people's intimate relationships. Hellevik et al (2015) found that adolescents in abusive relationships may be protective of either the perpetrator or the relationship.

Although children's exposure to domestic abuse is an identified priority for Child and Adolescent Mental Health services (CAMHS) (Department for Children, Schools and Families and Department of Health 2010) in England and Wales, there is little evidence available about the extent or nature of the service's work in this field (Stanley, 2011). A recent report from the Taskforce on Children and Young People's Mental Health and Wellbeing (Department of Health, 2015) mentions the harm arising from sexual exploitation and witnessing domestic violence but makes no mention of adolescents' experience of IPVA in their own relationships. Other professionals often look to CAMHs to offer therapeutic services to young people exposed to IPVA, either in the home or in their own relationships, but the service frequently appears inaccessible by virtue of its long waiting lists and high threshold criteria (Radford et al., 2011). The introduction of Improving Access to Psychological Therapies services for children and young people (CYP IAPT) (Wolpert et al., 2012) may offer opportunities for extending CAMHS' work to explicitly address IPVA in adolescent relationships and a recent strategy document from the independent Mental Health Taskforce (2016) recommended that CYP IAPT services be rolled out across England by 
2018. However, adolescent IPVA does not, as yet, seem to be an explicit theme in the work of these new services.

\section{Role of schools and mentors}

As noted above, since most prevention programmes are delivered in schools (Stanley et al 2015a), education also provides an appropriate setting for interventions to be delivered to those who have experienced IPVA. Whilst teachers are less likely to have the confidence or skills for this type of work (NSPCC and the Association of Teachers and Lecturers, 2014), schools are increasingly employing onsite counsellors, some of whom are provided by organisations that have relevant expertise in teenage IPVA. In some areas of the UK, CAMHS services are located in schools. However, given adolescent concerns about visibility and their desire to be able to access support services without it coming to the attention of their peers (Hellevik et al, 2015), care and planning needs to be given as to where these services are located and how they are accessed. The boundaries of confidentiality also need to be clearly drawn in respect of both a young person's family and other services such as the police and social workers. Where the risks to the young person are judged to be serious, schools may need to refer a young person to children's social services and the police may need to be involved if a crime has been committed.

Interestingly, young people in Barter et al.'s (2009a) study reported disclosing to and receiving support about IPVA from school learning mentors whose intermediate position between the school's core teaching staff and the home was perceived as helpful. Similarly, Banister and Leadbeater (2007) describe an Australian group-mentoring programme which offered girls the opportunity to discuss dating violence and assisted them in distinguishing abusive relationships. The authors note that this form of support may be particularly valuable for girls who are alienated from their families and isolated by the abuse.

\section{Interventions for Young Perpetrators}

Gadd et al's (2014) account of the negative response of young male offenders with histories of severe levels of IPVA perpetration to the This Is Abuse campaign film indicates that young men whose abusive behaviours are persistent and highly violent will require more targeted and sustained interventions than those aimed at the general population of young people. There have been some initiatives that aim to adapt programmes designed for adult perpetrators of IPVA to a younger audience. The Caring Dads Programme which seeks to improve abusive men's parenting as well as addressing their violence has been delivered with some success to adult men (McConnell et al., 2014). It has recently been piloted with a small group of young fathers aged 18-24 with some promising early indications (St Michael's Fellowship, 2015). Respect, a voluntary organisation providing resources and services for perpetrators of domestic abuse, has produced a training programme and toolkit for practitioners who are delivering interventions to young people who use abuse in their relationships (http://respect.uk.net/work/respect-young-peoples-service/teen-relationshipabuse/). The Domestic Violence Project (DVIP) in London delivers YUVA, a one-to-one 
intervention for young people who use abusive behaviours in the same group (http://www.dvip.org/professionals-young-people.htm). However, at present, there is little robust evidence for the effectiveness of these interventions.

\section{Conclusion}

This paper has navigated a mixed landscape in respect of the knowledge on adolescent IPVA. Whilst there is a growing literature reporting prevalence and impact and an established body of knowledge on prevention in this field, there is very little published evidence, or indeed practice knowledge regarding interventions for either victims or perpetrators. The shortfall in relevant services is a matter of concern, particularly since this review shows an association between IPVA and substance misuse, depressive symptoms, PTSD, eating disorders and suicidal thinking and behaviour in adolescents. Furthermore, the current expansion of preventative interventions is likely to increase disclosure and identification of interpersonal violence in young people's lives (Stanley et al., 2015b). A lack of service provision leaves adolescents and their families struggling to manage a range of mental health disorders and places frontline professionals, such as teachers who might be the first recipients of disclosures, in a position where they themselves lack the skills and knowledge to offer appropriate interventions but are unable to signpost young people to appropriate services. Moreover, a failure to offer appropriate interventions in adolescence makes it likely that experiences of both victimisation and perpetration will continue through into adulthood with the associated impacts on the mental health of the next generation of parents and children.

The independent/non-profit sector provides some examples of embryonic services for adolescents currently experiencing or using IPVA. These emerging approaches need to be supported and tested in order that interventions that are both effective and acceptable to young people can be identified and disseminated. Gender appears to be a key variable which mediates the effects of IPVA but there may be other important characteristics of young people to take into account when designing interventions; these might include sexuality, ethnicity, disability, age and mental health disorder or needs. In the past, professionals in health, education and social care services may have been guilty of dismissing or minimising distress in adolescent relationships. We now need to learn to pay careful attention to its forms and the context in which it arises.

\section{References}

included in the rapid review

Ackard, D. M., Eisenberg, M. E. and Neumark-Sztainer, D. (2007) Long-term impact of adolescent dating violence on the behavioral and psychological health of male and female youth. The Journal of Paediatrics, 151, pp.476-481. 
Ackard, D. M. and Neumark-Sztainer, D. (2002) Date violence and date rape among adolescents: associations with disordered eating behaviors and psychological health. Child Abuse Neglect., 26 (5) pp.455-473.

Ackard, D. M., Neumark-Sztainer, M. E., and Hannan, P.J. (2003) Dating violence among a nationally representative sample of adolescent girls and boys: associations with behavioral and mental health, J Gender-Specific Med, 6, pp.39-48.

Ansara, D. L. and Hindin, M. J. (2010) 'Exploring gender differences in the pattern of intimate partner violence in Canada: a latent class approach', Journal of Epidemiology and Community Health, 64, pp. 849-854.

Barter, C. (2009) In the Name of Love; Exploitation and violence in teenage dating relationships. British Journal of Social Work, 39, (2), pp. 211-232.

Barter, C., McCarry, M., Berridge, D. and Evans, K. (2009a) Partner Exploitation and Violence in Teenage Intimate Relationships, London, NSPCC.

Barter, C., Stanley, N., Wood, M., Aghtaie, N., Larkins, C., Øverlien, C. and Lesta, S. et al (2015). Safeguarding Teenage Intimate Relationships (STIR): Connecting online and offline contexts and risks. Research Report (Retrieved 27/10/15 from:

http://stiritup.eu/wpcontent/uploads/2015/06/STIR-Exec-Summary-English.pdf.

Banister, E. and Leadbeater, B.J. (2007) 'To Stay or to Leave? How do mentoring groups support healthy dating relationships in high-risk girls?' In Leadbeater, B. and Way, N. (eds), Urban Girls Revisited: Building strengths. New York: New York University Press.

Banyard, V. L. and Cross, C. (2008) Consequences of teen dating violence: understanding intervening variables in ecological context. Violence Against Women, 14 (9): pp.998-1013.

$\sim$ Belshaw , S., Siddique, J., Tanner, J. and Osho, S. (2012) The relationship between dating violence and suicidal behaviours in a national representative sample of adolescents, Violence and Victims, 27 (4), pp. 580-591.

Bonomi, A. E., Anderson, M. L., Nemeth, J., Rivara, F. P. and Buettner, C. (2013). History of dating violence and the association with late adolescent health. BMC Public Health, 13, 821.

Borowsky, I. W., Ireland, M. and Resnick, M. D. (2001). Adolescent suicide attempts: Risks and protectors. Pediatrics, 07, pp.485-493.

Brown, A., Cosgrave, E., Killackey, E., Purcell, R., Buckby, J., Yung, A. et al (2009) Longitudinal association of adolescent dating violence with psychiatric disorders and functioning, Journal of Interpersonal Violence, 24 (1) pp.1964-1979.

Callahan, M, R., Tolman, R, M. and Saunders, D, G. (2003) Adolescent dating violence victimization and psychological well-being. J Adolesc Res, 18 (6), pp. 664-681. 
$\sim$ Cha, S., Ihongbe, T. O., and Masho, S. W. (2016). Racial and gender differences in dating violence victimization and disordered eating among US high schools. Journal of Women's Health, Feb 2016 ahead on print.

Coker, A, L., McKeown, R, E., Sanderson, M, Davis, K, E., Valois, R, F. and Huebner, E, S. (2000) Severe dating violence and quality of life among South Carolina high school students. Am J Prev Med, 19 (4), pp. 220-227.

Connell, R, W. (1987) Gender and Power. Sydney, Allen and Unwin.

Cutter-Wilson, E. and Richmond, T. (2011) Understanding Teen Dating Violence: Practical screening and intervention strategies for pediatric and adolescent healthcare providers. Current Opinion in Pediatrics, 23(4), pp. 379-383.

Decker, M. R., Peitzmeier, S., Olumide, A., Acharya, R., Ojengbede, O., Covarrubias, L., ... $\&$ Brahmbhatt, H. (2014). Prevalence and health impact of intimate partner violence and nonpartner sexual violence among female adolescents aged 15-19 years in vulnerable urban environments: a multi-country study. Journal of Adolescent Health, 55(6), S58-S67.

Department of Health (2015) Future in mind: Promoting, protecting and improving our children and young people's mental health and wellbeing. London: Department of Health.

Department for Children, Schools and Families (DCSF) and Department of Health (2010) Keeping Children and Young People in Mind: The government's full response to the Independent Review of CAMHS. Nottingham: DCSF.

Department for Education (2012) Tackling Child Sexual Exploitation: National Action Plan Progress Report. Department for Education: London.

Draucker, C. B. and Martsolf, D. S. (2010). The role of electronic communication technology in adolescent dating violence. Journal of Child and Adolescent Psychiatric Nursing, 23(3), pp.133-142.

—Eaton, D. K., Davis, K. S., Barrios, L., Brener, N. D., \& Noonan, R. K. (2007). Associations of dating violence victimization with lifetime participation, co-occurrence, and early initiation of risk behaviors among US high school students. Journal of interpersonal violence, 22(5), pp. 585-602.

Ellis, J., Downe, S., Farrelly, N., Hollinghurst, S. and Stanley, N. (2015) School-based Prevention and the Disclosure of Domestic Violence: A Can of Worms? In Stanley, N. and Humphreys, C. (eds) Domestic Violence and Protecting Children: New Thinking and Approaches. London: Jessica Kingsley.

Exner-Cortens, D., Eckenrode, J. and Rothman, E. (2012) Longitudinal associations between teen dating violence victimization and adverse health outcomes. Pediatrics.12 (5), pp.71-78 
Featherstone, B. and Evans, H. (2004) Children experiencing maltreatment: who do they turn to? London, NSPCC.

Feder, G., Ramsay, J., Dunne, D., Rose, M., Arsene, C., Norman, R., Kuntze, S., Spencer, A., Bacchus, L., Hague, G., Warburton, A. and Taket, A. (2009). How far does screening women for domestic (partner) violence in different health-care settings meet criteria for a screening programme? Systematic reviews of nine UK National Screening Committee criteria. Health Technology Assessment, 13 (16), pp.137-347.

Fellmeth, G.L.T., Heffernan, C., Nurse, J., Habibula, S. and Sethi, D. (2013). Educational and skills-based interventions for preventing relationship and dating violence in adolescents and young adults. Cochrane Database of Systematic Reviews, 2013(6).

Foshee, V. (1996). Gender differences in adolescent dating abuse prevalence, types, and injuries. Health Education Research, 11(3), pp.275-286.

Fox , C. L., Corr, M. L., Gadd, D., and Butler, I. (2013). Young teenagers' experiences of domestic abuse. Journal of Youth Studies, 17(4), pp.510-526.

Gadd, D., Corr, M., Fox, C. L., and Butler, I. (2014). This is abuse... or is it? domestic abuse perpetrators' responses to anti-domestic violence publicity. Crime, Media, Culture, 10(1), pp. 3-22.

Ganann, R., Ciliska, D. and Thomas, H. (2010) Expediting systematic reviews: methods and implications of rapid reviews. Information Science, 5 pp. 1-10.

Garrison, C. Z., McKeown, R. E., Valois, R. F. and Vincent, M. L. (1993) Aggression, substance use, and suicidal behaviors in high school students. American Journal of Public Health, 83, pp.179-184.

Goldberg, N. G. and Meyer, I. H. (2013) Sexual orientation disparities in history of intimate partner violence results from the Californian Health Interview Survey, Journal of Interpersonal Violence, 28 (5), pp. 1109-1118.

Gorin, S. (2004) Understanding What Children Say: Children's Experiences of Domestic Violence, Parental Substance Misuse and Parental Mental Health Problems. London:

National Children's Bureau.

Halpern, C., Young, M., Waller, M., Martin, S. and Kupper, L. (2004) Prevalence of partner violence in same-sex romantic relationships in a national sample of adolescents, Journal of Adolescent Health, 35, pp. 124-131.

Hamby, S., Finkelhor, D. and Turner, H. (2012). Teen dating violence: Co-occurrence with other victimizations in the national survey of children's exposure to violence, Psychology of Violence, 2 (2), pp.111-124. 
Haynie, D., Farhat, T., Brooks-Russell, A., Wang, J., Barbieri, B. and Lannotti, R. (2013) Dating violence perpetration and victimisation among US adolescents: prevalence, patterns and associations with health complaints and substance use, J Adolesc Health, 53 (2) pp. 194201.

Hellevik, P, M., Överlien, C., Authors, C., Wood, M., Aghtaie, N., Larkins, C. and Stanley, N. (2015) Traversing the Generational Gap: Young People's Views on Intervention and Prevention of Teenage Intimate Partner Violence. In Stanley, N. and Humphreys, C. (eds) Domestic Violence and Protecting Children: New Thinking and Approaches. London: Jessica Kingsley.

Hester, M. and Westmarland, N. (2005). Tackling domestic violence: Effective interventions and approaches. London: Home Office Research, Development and Statistics Directorate.

Holt, M. K. and Espelage, D. L. (2005) Social support as a moderator between dating violence victimization and depression/anxiety among African American and Caucasian adolescents, School Psychology Review, 34, pp. 309-328.

Home Office (2013) Domestic Violence and Abuse. Retrieved from https://www.gov.uk/guidance/domestic-violence-and-abuse

Howard, D. E. and Wang, M. Q. (2003). Risk profiles of adolescent girls who were victims of dating violence. Adolescence, 38(149), pp. 1-14

Howard, D. E., Wang, M. Q., and Fang, Y. (2007). Psychosocial factors associated with reports of physical dating violence among US adolescent females. Adolescence, pp. 42(166), 311-24.

Howarth, E., Moore, T, Welton, N. J., Lewis, N., Stanley, N., MacMillan, HL, Shaw, A., Hester, M, Bryden, P, Feder, GS (2016 forthcoming) IMPRoving Outcomes for children exposed to domestic ViolencE (IMPROVE): An evidence synthesis. Public Health Research.

Jackson, S. M., Cram, F. and Seymour, F. W. (2000). Violence and sexual coercion in high school students' dating relationships. Journal of Family Violence, 15 (1), pp.23-36.

Jouriles, E. N., Garrido, E., Rosenfield, D., \& McDonald, R. (2009). Experiences of psychological and physical aggression in adolescent romantic relationships: Links to psychological distress. Child abuse \& neglect, 33(7), 451-460.

Katz, J., Heisterkamp, H.A. and Fleming, W. M. (2011). The social justice roots of the Mentors in Violence Prevention model and its application in a high school setting. Violence Against Women, 17 (6), pp. 684-702. 
Kreiter, S. R., Krowchuk, D. P., Woods, C. R., Sinal, S. H., Lawless, M. R. and Durant, R. H. (1999). Gender differences in risk behaviors among adolescents who experience date fighting. Pediatrics, 104 (6), pp. 1286-1292.

Lehrer, J.A., Buka, S., Gortmaker, S. and Shrier, L. A. (2006) Depressive symptomatology as a predictor of exposure to intimate partner violence among US female adolescents and young adults, Arch Pediatr Adolsc Med, 160, pp. 270-276.

Lormand, D. K., Markham, C. M., Peskin, M. F., Byrd, T. L., Addy, R. C., Baumler, E., \& Tortolero, S. R. (2013). Dating violence among urban, minority, middle school youth and associated sexual risk behaviors and substance use. Journal of school health, 83(6), pp. 415421.

Lundgren, R., \& Amin, A. (2015) Addressing intimate partner violence and sexual violence among adolescents: emerging evidence of effectiveness. Journal of Adolescent Health, 56, pp. 542-550.

Martin-Storey, A. (2015) Prevalence of Dating Violence among sexual minority youth: Variation across gender, sexual minority status identity and gender of sexual partners. Journal of Youth Adolescence, 44 (1) pp. 211-224.

Mass, C. D., Fleming, C. B., Herrenkohl, T. I. and Catalano, R. F. (2010) Childhood predictors of teen dating violence: a mixed methods study, J Interpersonal violence, 25 (2), pp. 131-149.

McCauley, H., Breslau, J., Saito, N. and Miller, E. (2015) Psychiatric disorders prior to dating initiation and physical dating violence age 21, Soc Psychiatry Psychiat Epidemio, 50, pp. 1357-1365.

McConnell, M., Barnard, M., Holdsworth, T. and Taylor, J. (2014) Caring Dads, Safer Children: Interim Evaluation Report. London: NSPCC. Retrieved from www.nspcc.org.uk/ globalassets/documents/evaluation-of-services/caring-dads-safer-children-interimreport. pdf, accessed on 22 May 2015.

McKeown, R. E., Garrison, C. Z., Cuffe, S. P., Waller, J. L., Jackson, K. L. and Addy, C. L. (1998). Incidence and predictors of suicidal behaviors in a longitudinal sample of young adolescents. The Journal of the American Academy of Child \& Adolescent Psychiatry, 37(6), pp. 612-619.

Mental Health Taskforce (2016). The Five Year Forward View for Mental Health. London: The Mental Health Taskforce.

Miller, E., Das, M., Tancredi, D.J., McCauley, H.L., Virata, M.C., Nettiksimmons, J., et al., (2014). Evaluation of a gender-based violence prevention program for student athletes in Mumbai, India. Journal of Interpersonal Violence, 29 (4), pp.758-78.

Miller, E., Tancredi, D.J., McCauley, H.L, Decker, M.R., Virata, M.C., Anderson, H.A., et al.,. (2012) "Coaching boys into men": a cluster-randomized controlled trial of a dating violence prevention program. Journal of Adolescent Health , 51(5), pp. 431-8. 
Mitra, M., Mouradian, V. and McKenna, M. (2013) Dating violence and associated health risks among high school students with disabilities, Matern Child Health, 17, pp.1088-1094.

Molidor, C., Tolman, R. M. and Kober, J. (2000). Gender and contextual factors in adolescent dating violence. Prevention Research, 7(1), pp.1-4.

Murrell, A. R., Christoff, K. A. and Henning, K. R. (2007). Characteristics of domestic violence offenders: Associations with childhood exposure to violence. Journal of Family Violence, 22, pp. 523-532.

National Institute for Health and Care Excellence (NICE). (2014). Domestic violence and abuse: How health services, social care and the organisations they work with can respond effectively. Retrieved from guidance.nice.org.uk/ph50

NSPCC and the Association of Teachers and Lecturers (ATL) (2013). Young people and relationship abuse: a survey of education professionals. Retrieved from https://www.atl.org.uk/Images/education-professional-survey-headline-results-nov-13.pdf

Olshen, E,. McVeigh, K. H., Wunsch-Hitzig, R. A. and Rickert, V. I. (2007) Dating violence, sexual assault, and suicide attempts among urban teenagers. Arch Pediatr Adolesc Med, 161(6), pp. 539-545

Olson, C. E., Rickert, V. I. and Davidson, L. L. (2004) Identifying and supporting young women experiencing dating violence: what health practitioners should be doing NOW. J Pediatr Adolesc Gynecol, 17, pp. 131-136.

Parker, E. M., Debnam, K., Pas, E. T., and Bradshaw, C. P. (2015). Exploring the link between alcohol and marijuana use and teen dating violence victimization among high school students the influence of school context. Health Education \& Behavior, 1090198115605308.

Public Health England and Association for Young People's Health (AYPH) (2015). Improving Young People's Health and Wellbeing: A Framework for Public Health. London: Public Health England.

Radford, L., Aitken, R., Miller, P., Ellis, J., Roberts, J. and Firkic, A. (2011) Meeting the Needs of Children Living with Domestic Violence in London. Project Report. London: NSPCC.

Raiford, J. L., Wingood, G. M., \& DiClemente, R. J. (2007). Prevalence, incidence, and predictors of dating violence: A longitudinal study of African American female adolescents. Journal of Women's Health, 16(6), 822-832.

Reid Howie Associates. (2002). Evaluation of the zero tolerance 'Respect' pilot project. Edinburgh: Scottish Executive.

Resnick, M. D., Bearman, P. S., Blum, R. W., Bauman, K. E., Harris, K. M., Jones, J., et al. (1997). Protecting adolescents from harm. Findings from the National Longitudinal Study on Adolescent Health. Journal of the American Medical Association, 278, pp. 823-832. 
Rickert, V., Davison, L., Breitbard, V., Jones, K., Palmetto, N., Rottenberg, L., Tanenhaus, J. and Stevens, L. (2009). A Randomized Trial of Screening for Relationship Violence in Young Women. Journal of Adolescent Health, 45: pp.163-170.

Rothman, E. F., McNaughton Reyes, L., Johnson, R. M. and LaValley, M. (2012). Does the alcohol make them do it? Dating violence perpetration and drinking among youth, Epidemiol Rev, 34, pp.103-119.

SafeLives (2013). Practice briefing for IDVAs Working with young people experiencing relationship abuse. Retrieved from

http://www.safelives.org.uk/sites/default/files/resources/Young\%20People\%20practice\%20br iefing\%20for\%20IDVAs\%20FINAL.pdf

SafeLives (2015). Practice briefing for professionals working with young people experiencing or at risk of online abuse. Retrieved from http://www.safelives.org.uk/sites/default/files/resources/Practice\%20briefing\%20for\%20you ng\%20people\%20-\%20online\%20abuse\%20FINAL.pdf

Schad, M. M., Szwedo, D. E., Antonishak, J., Hare, A. and Allen, J. P. (2008). The broader context of relational aggression in adolescent romantic relationships: predictions from peer pressure and links to psychosocial functioning. J Youth Adolesc, 37(3), pp. 346-358

$\sim$ Silverman, J. G., Raj, A., Mucci, L. A. and Hathaway, J. E. (2001). Dating violence against adolescent girls and associated substance use, unhealthy weight control, sexual risk behavior, pregnancy, and suicidality. JAMA. 286(5), pp. 572-579.

Singer, M. I., Anglin, T. M., Song, L. Y., and Lunghofer, L. (1995). Adolescents' exposure to violence and associated symptoms of psychological trauma. Journal of the American Medical Association, 273, pp. 477-482.

St Michael's Fellowship (2015). The Caring Dads programme with young fathers in Lambeth. Retrieved from http://www.stmichaelsfellowship.org.uk/uploads/media/17/16156.pdf

Stanley, N. (2011). Children Experiencing Domestic Violence: A Research Review. Dartington: RIP.

Stanley, N., Ellis, J., Farrelly, N., Hollinghurst, S., Bailey, S. and Downe, S. (2015a). Preventing Domestic Abuse for Children and Young People (PEACH): A Mixed Knowledge Scoping Review. Public Health Research, 3, 7. Retrieved from http://www.journalslibrary.nihr.ac.uk/phr/volume-3/issue-7\#abstract

Stanley, N., Ellis, J., Farrelly, N., Hollinghurst, S. and Downe, S. (2015b). Preventing domestic abuse for children and young people: A review of school-based interventions. Children and Youth Services Review, 59, 120-131.

Stanley, N., Ellis, J., Farrelly, N., Hollinghurst, S., Bailey, S. and Downe, S. (under review). 'What matters to someone who matters to me': Using Media Campaigns with Young People to Prevent Interpersonal Violence and Abuse. 
Stonard, K., Bowen, E., Lawrence, T. and Price, S. A. (2014). The relevance of technology to the nature, prevalence and impact of Adolescent Dating Violence and Abuse: A research synthesis. Aggression and Violent Behavior, 19 (4), pp.390-417.

Swahn, M. H., Simon, T. R., Hertz, M. F., Arias, I., Bossarte, R. M., Ross, J. G., et al. (2008). Linking dating violence, peer violence, and suicidal behaviors among high-risk youth. American Journal of Preventive Medicine, 34, pp. 30-38.

Swann, M., Bossarte, R. and Sullivent, E. (2008). Age of alcohol use initiation, suicidal behaviour, and peer and dating violence victimisation and perp amongst high risk seventhgrade adolescents, Paediatrics, 121 (2), pp. 297-305.

Temple, J. R., \& Freeman, D. H. (2011). Dating violence and substance use among ethnically diverse adolescents. Journal of interpersonal violence,26(4), 701-718.

Thompson, K. M., Wonderlich, S. A., Crosby, R. D. and Mitchell, J. E. (2001), Sexual violence and weight control techniques among adolescent girls. Int. J. Eat. Disord., 29: 166176.

Van Dulmen, M. H. M., Klipfel, K. M., Mata, M. D, et al. (2012) Cross-lagged effects between intimate partner violence victimization and suicidality from adolescence into adulthood. J Adolesc Health, 51(5) pp.510-516.

Vezina, J. and Hebert, M. (2007) Risk factors for victimization in romantic relationships of young women: A review of empirical studies and implications for prevention, Trauma Violence and Abuse, 8, pp. 33-66

Volpe, E. M., Hardie, T. and Cerulli, C. (2012) Associations among depressive symptoms, dating violence, and relationship power in urban adolescent girls, JOGNN, 41, pp.506-518.

Walby, S. and Allen, J. (2004) Domestic Violence, Sexual Assault and Stalking: Findings from the British Crime Survey, London: Home Office Research, Development and Statistics Directorate.

Westwood, J. and Larkins, C. (2015) Advocacy for Children and Young People Experiencing Domestic Violence. In Stanley, N. and Humphreys, C. (eds) Domestic Violence and Protecting Children: New Thinking and Approaches. London: Jessica Kingsley.

Whitaker, D., Morrison, S., Lindquist, C., Hawkins, S., O'Neil, J., Nesius, A., Mathew, A. and Reese, L. (2006). A critical review of interventions for the primary prevention of perpetration of partner violence. Aggress Violent Behav,11 (2), pp.151-166. 
Whitefield, C. L., Anda, R. F. and Dube, S. R. (2003) Violent childhood experiences and the risk of intimate partner violence in adults: Assessment in a large health maintenance organization, Journal of Interpersonal Violence, 18 (2), pp.166-185.

Wincentak, K., Connolly, J., Card, N. (2016) Teen Dating Violence: A Meta-Analytic Review of Prevalence Rates. Psychology of Violence, Apr 11, 2016 http://dx.doi.org/10.1037/a0040194

Wolfe, D.A., Crooks, C.V., Jaffe, P.G., Chiodo, D., Hughes, R., Ellis, W., Stitt, L. and Donner, A. (2009). A school-based program to prevent adolescent dating violence a cluster randomized trial. Archives of Pediatrics \& Adolescent Medicine, 163, pp. 692-9.

Wolpert, M., Fugard, A.J.A., Deighton, J. and Görzig, A. (2012). Routine outcomes monitoring as part of children and young people's Improving Access to Psychological Therapies (CYP IAPT) - improving care or unhelpful burden? Child and Adolescent Mental Health, 17, 3, pp.129-130.

Wolitzky-Taylor, K. B., Ruggiero, K. J., Danielson, C. K., Resnick, H. S., Hanson, R. F., Smith, D. W., ... Kilpatrick, D. G. (2008). Prevalence and correlates of dating violence in a national sample of adolescents, Journal of the American Academy of Child and Adolescent Psychiatry, 47(7) pp. 755-762.

Wood, M., Barter, C. and Berridge, D. (2010) Standing on my own two feet: Disadvantaged young people and partner violence. London, NSPCC.

Wood, M., Barter, C., Stanley, N., Aghtaie, N. and Larkins, C. (2015). Images across Europe: The sending and receiving of sexual images and associations with interpersonal violence in young people's relationships. Children and Youth Services Review, 59, pp.149-160.

Woods, E. R., Lin, Y. G., Middleman, A., Beckford, P., Chase, L. and DuRant, R. H. (1997). The associations of suicide attempts in adolescents. Pediatrics, 99, pp.791-796.

World Health Organisation (WHO) (2009) Violence Prevention, the Evidence: Changing cultural and social norms supportive of violent behaviour. Geneva: WHO.

World Health Organisation (WHO) (2015) Preventing youth violence: an overview of the evidence. Geneva: WHO.

Zaha, R., Helm, S., Baker, C., \& Hayes, D. (2013). Intimate partner violence and substance use among Hawai 'i youth: An analysis of recent data from the Hawai 'i Youth Risk Behavior Survey. Substance use \& misuse, 48 (1-2), pp.11-20.

Zweig, J. M., Dank, M., Yahner, J. and Lachman, P. (2013). The rate of cyber dating abuse among teens and how it relates to other forms of teen dating violence.

Journal of Youth and Adolescence, 42 (7) pp.1063-1077. 